\title{
Atrial septal defect and calcification of the tricuspid valve
}

\author{
Jon D. Cooksey, Brent M. Parker, and Clarence S. Weldon \\ From the Departments of Medicine and Cardiothoracic Surgery of the Washington \\ University School of Medicine, St. Louis, Missouri, U.S.A.
}

\begin{abstract}
A patient with atrial septal defect and calcification of the tricuspid valve is presented. The calcification was first detected by fluoroscopy and its presence was confirmed during cardiac surgery. To our knowledge, this combination has not been reported previously. Possible factors contributing to the calcification are ageing, excessive blood flow, and raised right ventricular pressure.
\end{abstract}

Calcification of the tricuspid valve is rare. The purpose of this paper is to report a patient with an ostium secundum atrial septal defect and calcification of the tricuspid valve. We have been unable to find a similar case reported in English.

\section{Case report}

A 44-year-old man was admitted to Barnes Hospital in August 1968 for evaluation of a congenital heart lesion. A heart murmur had been noted since early childhood, and he was deferred from military service at age 18 years for this reason. There was no history of rheumatic fever. In his third decade, dyspnoea with heavy exertion began. In January 1968, rapid irregular heart action, orthopnoea, and increased dyspnoea when walking were noted. Atrial flutter was converted to sinus rhythm by electrical countershock. Digitalis, diuretics, and quinidine were administered with only slight relief of his dyspnoea. On admission to Barnes Hospital in August 1968, he could walk only half a block and was sleeping on two pillows. The patient's 15-yearold daughter is known to have an atrial septal defect.

On physical examination, the apical impulse was felt $2 \mathrm{~cm}$. lateral to the mid-clavicular line in the fifth left intercostal space. There was a moderate left parasternal heave. A widely fixed split of the second heart sound was heard at the second left interspace, with accentuation of the pulmonary component. A grade 2/6 short systolic ejection murmur was present along the left sternal border and at the second left interspace.

1 This work was supported in part by grants from the National Heart Institute of the National Institutes of Health, U.S. Public Health Service.
Haemoglobin was $14.7 \mathrm{~g} / 100 \mathrm{ml}$. and serology was negative.

The electrocardiogram showed right axis deviation, complete right bundle-branch block, frequent atrial and ventricular premature contractions, and digitalis effect.

The chest $x$-ray showed enlargement of the right ventricle and atrium and pulmonary hyperaemia. There was no evidence of left atrial enlargement and no calcification was observed.

Cardiac catheterization results are recorded in the Table. A left-to-right shunt was detected at the atrial level with a pulmonary/systemic flow ratio of $2.5 / \mathrm{I}$, as determined by the Fick method. Pulmonary artery pressure was slightly raised. A surprising finding on fluoroscopy was a heavy ring of calcification in the region of the tricuspid valve (Fig.). Angiography showed a large right atrium, right ventricle, and pulmonary artery. There was no mitral insufficiency during a left ventricular angiocardiogram.

Operation was performed using cardiopulmonary bypass. A $2.5 \times 2.5 \mathrm{~cm}$. secundum type atrial septal defect was closed with a running everting 4-0 Tefdek suture. The everted margins of the defect were then over-sewn with the same suture material. The tricuspid valve contained moderately heavy calcification extending from the entire fibrous ring into the valve leaflets, but not involving the free edge. Calcification was most obvious in the posterior leaflet. The valve leaflets were not distorted and the valve appeared to be competent. The chordae tendineae and papillary muscles were grossly normal.

The post-operative course was complicated by a right lower lobe pneumonia which responded to antibiotics. One week after operation numbness developed suddenly in the right foot, with loss of pulses below the popliteal artery. A clot 
TABLE Cardiac catheterization data

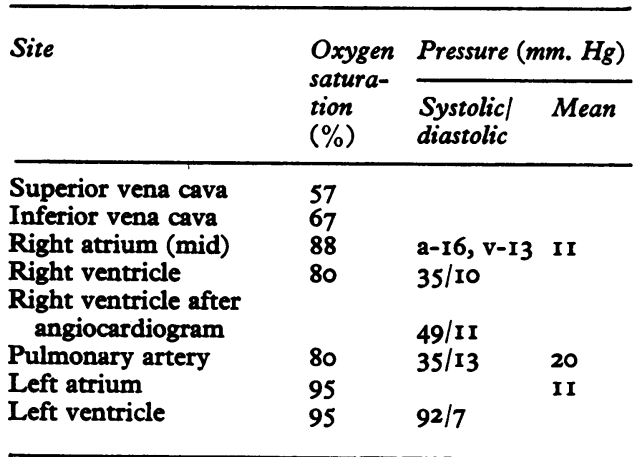

was removed from the popliteal artery by catheter embolectomy through the right femoral artery. Subsequent convalescence was uneventful. An episode of atrial flutter with 2 : I AV block necessitated readmission three days after discharge. Electrical conversion was performed successfully and he has remained well since.

FIG. $A$ Left anterior oblique projection showing heavy calcification (arrow) in the region of the tricuspid valve. Note that the area of calcification is anterior to the mitral valve and inferior to the aortic valve region.

A

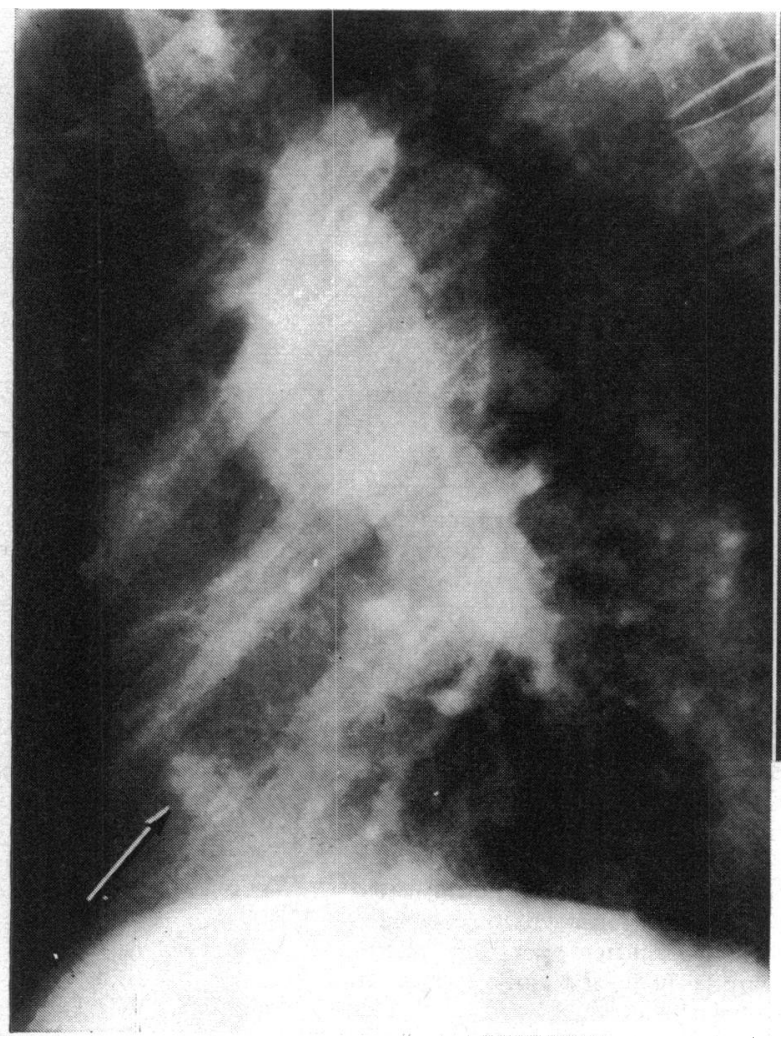

\section{Discussion}

Calcification of the tricuspid valve is unusual in any type of heart disease (Cooley and Schreiber, 1967; J. E. Edwards, 1969, personal communication; J. L. Titus, 1969, personal communication). Though pathological abnormality of the tricuspid valve occurs in as many as 22 per cent of patients with rheumatic heart disease (Cooke and White, 194I), calcification is rarely present (Tillotson and Steinberg, 1962; Epstein, 1940; Hollman, 1957). Starr, Herr, and Wood (1966) found no gross calcification in 31 tricuspid valves removed at operation from patients with rheumatic heart disease.

Tricuspid valve calcification is also rare in congenital heart disease. Hollman (1957) described calcification in the tricuspid valve in a 46-year-old man with severe pulmonary valve stenosis. He suggested that the calcification could have been due to congenital tri-

FIG. $B$ A magnified view of the tricuspid valve calcification (arrows) in the left anterior oblique projection.

$B$

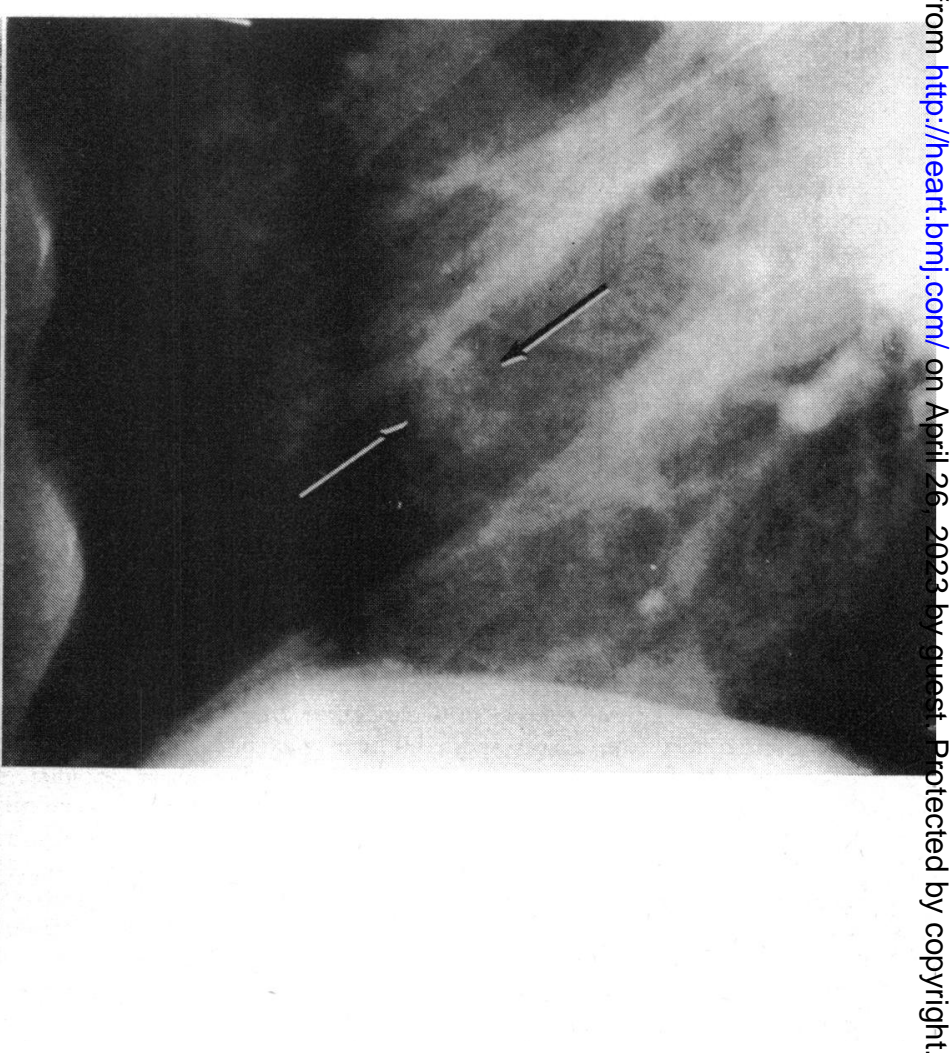


cuspid valve disease or possibly to the longcontinued high closing pressure to which the valve was subjected. Edwards et al. (1965) have observed fibrosis of the tricuspid valve and thickening of the chordae tendineae in pulmonary stenosis with intact ventricular septum with survival beyond infancy. Focal calcification was present in the tricuspid valve though not of a degree to be visualized by fluoroscopy. Sautter, Emanuel, and Doege (1965) described irregularly distributed calcium in a stenotic tricuspid valve in a 75year-old woman who died from tetralogy of Fallot. The calcification was attributed to high pressure in the right ventricle.

Two experienced cardiac pathologists have not observed calcification of the tricuspid valve in atrial septal defect (J. E. Edwards, I969, personal communication; J. L. Titus, 1969, personal communication), and we have been unable to find a published reference to this association. In his review of atrial septal defect, Roesler (1934) reported that the AV valves and chordae tendineae showed thickening in 48 of 62 cases. Involvement was primarily of the mitral valve though isolated involvement of the tricuspid valve was also reported. He did not describe calcification.

The number of reported cases of tricuspid valve calcification is too small to allow any surmise regarding the cause of the calcification. In our case the only possible factors seem to be ageing and excessive blood flow across the tricuspid valve with slightly raised right ventricular pressure. McMillan and Lev (1964), in a study of the effect of ageing on the heart valves, noted thickening of the aortic and mitral valve leaflets in the fourth decade and atherosclerotic plaques in both valves slightly later. These changes progressed with ageing and were occasionally associated with calcification. Alterations in the tricuspid and pulmonary valves were much less obvious and no atherosclerotic plaques or calcifications were seen. These ageing changes in heart valves were thought to be secondary to blood flow and pressure tension relations.

The arterial embolus occurring in our patient during the early post-operative period warrants comment. Embolic complications of atrial septal defect repairs have been recently reported by Hawe et al. (1969) to occur with moderate frequency especially in patients older than 40 and in those in whom a prosthesis is used to close the defect. These authors recommended that older adult patients should receive anticoagulant therapy for an indefinite period after repair of an atrial septal defect.

\section{References}

Cooke, W. T., and White, P. D. (194I). Tricuspid stenosis; with particular reference to diagnosis and prognosis. British Heart fournal, 3, 147.

Cooley, R. N., and Schreiber, M. H. (1967). Radiology of the Heart and Great Vessels, 2nd ed., pp. 4 and 445. Williams and Wilkins, Baltimore.

Edwards, J. E., Carey, L. S., Neufeld, H. N., and Lester, R. G. (1965). Congenital Heart Disease: Correlation of Pathologic Anatomy and Angiocardiography, Vol. 2, p. 6r4. W. B. Saunders, Philadelphia and London.

Epstein, B. S. (1940). Comparative study of valvular calcifications in rheumatic and in nonrheumatic heart disease. Archives of Inter nal Medicine, 65, 279.

Hawe, A., Rastelli, G. C., Brandenburg, R. O., and McGoon, D. C. (1969). Embolic complications following repair of atrial septal defects. Circulation, 39-40, Suppl. I, 185 .

Hollman, A. (1957). The anatomical appearance in rheumatic tricuspid valve disease. British Heart fournal, 19, 211.

McMillan, J. B., and Lev, M. (1964). The aging heart. II. The valves. Fournal of Gerontology, 19, I.

Roesler, H. (1934). Interatrial septal defect. Archives of Internal Medicine, 54, 339.

Sautter, R. D., Emanuel, D. A., and Doege, K. H. (I965). Association of pulmonary valvular stenosis and muscular ventricular septal defect. Report of a case in a patient aged 75 years. American fournal of Cardiology, 16, 743.

Starr, A., Herr, R., and Wood, J. (1966). Tricuspid replacement for acquired valve disease. Surgery, Gynecology and Obstetrics, 122, 1295.

Tillotson, P. M., and Steinberg, I. (I962). Roentgen features of rheumatic tricuspid stenosis. American Yournal of Roentgenology, Radium Therapy, and Nuclear Medicine, 87, 948. 